\title{
Can vegetation index track the interannual variation in gross primary production of temperate deciduous forests?
}

\author{
Fan Liu' ${ }^{1,2}$, Chuankuan Wang ${ }^{1,2}$ and Xingchang Wang ${ }^{1,2^{*}}$
}

\begin{abstract}
Background: Vegetation indices (VIs) by remote sensing are widely used as simple proxies of the gross primary production (GPP) of vegetation, but their performances in capturing the inter-annual variation (IAV) in GPP remain uncertain.

Methods: We evaluated the performances of various VIs in tracking the IAV in GPP estimated by eddy covariance in a temperate deciduous forest of Northeast China. The VIs assessed included the normalized difference vegetation index (NDVI), the enhanced vegetation index (EVI), and the near-infrared reflectance of vegetation (NIRV) obtained from tower-radiometers (broadband) and the Moderate Resolution Imaging Spectroradiometer (MODIS), respectively.

Results: We found that 25\%-35\% amplitude of the broadband EVI tracked the start of growing season derived by GPP ( $R^{2}: 0.56-0.60$, bias < 4 d), while 45\% (or 50\%) amplitudes of broadband (or MODIS) NDVI represented the end of growing season estimated by GPP $\left(R^{2}: 0.58-0.67\right.$, bias $<3 \mathrm{~d}$ ). However, all the VIs failed to characterize the summer peaks of GPP. The growing-season integrals but not averaged values of the broadband NDVI, MODIS NIRV and EVI were robust surrogates of the IAV in GPP $\left(R^{2}: 0.40-0.67\right)$.

Conclusion: These findings illustrate that specific VIs are effective only to capture the GPP phenology but not the GPP peak, while the integral VIs have the potential to mirror the IAV in GPP.
\end{abstract}

Keywords: NDVI, EVI, NIRv, photosynthesis, phenology

\section{Introduction}

Gross primary production (GPP), i.e. total carbon (C) fixed by vegetation photosynthesis, is the largest component of the global C cycle (Beer et al. 2010). It is also tightly related to many ecosystem functions, including ecosystem and soil respiration (Baldocchi et al. 2018; Janssens et al. 2001), vegetation growth (Körner 2015), water loss through transpiration (Baldocchi 2020; Zhou et al. 2014), etc. Due to the complex response of vegetation to climatic perturbations, there is a large inter-

\footnotetext{
* Correspondence: xcwang_cer@nefu.edu.cn

${ }^{1}$ Center for Ecological Research, Northeast Forestry University, Harbin 150040, China

${ }^{2}$ Key Laboratory of Sustainable Forest Ecosystem Management - Ministry of Education, Northeast Forestry University, Harbin 150040, China
}

annual variation (IAV) in global C budget (Ahlström et al. 2015); and the IAV in GPP is still difficult to be accurately estimated using current land surface models (Piao et al. 2019; Xia et al. 2020), which in turn hindered the prediction of future climate-C cycle feedback (Ryu et al. 2019).

Remote sensing vegetation index (VI, often called greenness), such as the normalized difference vegetation index (NDVI) and enhanced vegetation index (EVI), are widely used as direct proxies of GPP (Rahman et al. 2005; Wang et al. 2004; Zhou et al. 2001), or as key inputs in the light-use efficiency model for simulating GPP (Running et al. 2004). A newly proposed index, the nearinfrared reflectance of vegetation (NIRv, the product of NDVI and near-infrared reflectance), is demonstrated to 
be a good proxy of GPP at monthly to annual scales across FLUXNET sites (Badgley et al. 2019; Wang et al. 2021). Compared with NDVI, the NIRv untangles the confounding effects of background brightness and the saturation in the dense canopy (Badgley et al. 2019; Badgley et al. 2017). However, capturing the IAV and long-term trends in GPP remains a challenge to satellite data. The ability in surrogating annual GPP diverges among VIs, and even varies with integrating or averaging period of VI. For example, the annual mean VIs only explained the variations in GPP for deciduous broadleaved forests by $9-50 \%$, with a slightly better performance of NIRv than NDVI and EVI (Huang et al. 2019). When using the VI during growing season, the integral NDVI was tightly correlated with GPP across vegetation types $\left(R^{2}=0.80\right)$ (Park et al. 2016). In contrast, the growingseason mean NDVI and EVI only explained $<10 \%$ of the GPP variations for the deciduous broadleaved forests in the La Thuile dataset (Verma et al. 2014). Moreover, considering the seasonal asynchrony between canopy greenness and $\mathrm{C}$ uptake, different growing-season definitions for VI (for example, the various thresholds of VI magnitude) may change the VI-GPP relationship, which has not yet been tested. Collectively, it is essential to comprehensively evaluate the relationships between annual GPP and different types of integrated or averaged VIs with various definitions of growing-season.

Accurately modeling the canopy GPP phenology by VI phenology is another significant question, as the GPP phenology is important for understanding changes in the $C$ sequestration, surface energy and water balances (D'Odorico et al. 2015). The relationship between VI (NDVI or EVI) and GPP phenology diverges across deciduous forest ecosystems (D'Odorico et al. 2015), with the root mean square error of the linear model between VI and GPP phenology across site-years varying from 13 weeks in the literature (Balzarolo et al. 2019; Gonsamo et al. 2012; Peng et al. 2017a; Peng et al. 2017b). Generally, the relationship between VI and GPP phenology in autumn is weaker than that in spring for deciduous forests (D'Odorico et al. 2015; Gonsamo et al. 2012; Yin et al. 2020), and EVI may outperform NDVI (Yin et al. 2020). Nevertheless, NIRv has been rarely used to capture the GPP phenology (Yin et al. 2020). Therefore, it is imperative to compare the abilities of various VIs for capturing GPP phenology. Furthermore, most studies use the same inflection point (i.e., the change of curvature) to define both VI and GPP phenology. However, the seasonal variations in VI and GPP are asynchronous, as VI responds differently to greenness, wetness and brightness dynamics (D'Odorico et al. 2015). For instance, the NDVI phenology based on the midpoint method agrees with the GPP phenology based on the start of slope point method better than does the NDVI phenology based on the start of slope point method (D’Odorico et al. 2015). To date, less work has been devoted to changing the definition of VI phenology to match with GPP phenology.

Whether the summer peak of VI can surrogate that of GPP is also a pending question, although we have known that the annual peak growth of vegetation is critical in characterizing the capacity of ecosystem production (Huang et al. 2018). As a pivotal physiological metric, the GPP peak based on eddy covariance (EC) dominates the IAV in GPP across the northern hemispheric ecosystems (Xia et al. 2015; Xu et al. 2019; Zhou et al. 2016; Zhou et al. 2017). In contrast, the NDVI peak plays a less important role than NDVI phenology in regulating the IAV in the integral NDVI (a proxy of GPP) for the broadleaf forests in northeastern China (Zhou 2020). Huang et al. (2018) reported that the global NDVI peak and modeled GPP peak did not change consistently after 1998 when charactering the long-term trend of vegetation growth. These discrepancies imply that the NDVI peak may not be an efficient surrogate of GPP peak. Although the EVI and NIRv are more sensitive to canopy variation in the dense vegetation than NDVI (Badgley et al. 2017; Huete et al. 2002), the relationship between the EVI or NIRv peak and GPP peak has rarely been explored.

The broadband VIs based on near-surface remote sensing have the advantages of high temporal resolution and little influences of the atmospheric perturbations (Liu et al. 2019a; Richardson et al. 2013). The seasonal broadband NDVI has been showed to be more related to GPP than Moderate Resolution Imaging Spectroradiometer (MODIS) NDVI in a Scots pine of Finland (Wang et al. 2004). However, the broadband VIs-GPP relationships at the interannual scale are still poorly evaluated.

In this study, the NDVI, EVI, and NIRv obtained from tower-radiometers and MODIS were used to track the IAV in GPP measured with the EC method in a temperate deciduous forest, Northeast China. We aimed to address the following questions: (1) How the VI type and definition of growing-season compromise the VI-GPP (flux) relationship? (2) Does the match between VI and GPP phenology vary with VI type and definition of phenology (definition threshold of VI magnitude) ? (3) Can the VI peak track the IAV in GPP peak?

\section{Materials and Methods}

\section{Site description}

The study was conducted at the Maoershan Forest Ecosystem Research Station of Northeast Forestry University, Northeast China with a continual monsoon climate $\left(45^{\circ} 24^{\prime} \mathrm{N}, 127^{\circ} 40^{\prime}\right.$ E, $400 \mathrm{~m}$ a.s.l.). The mean ( \pm standard deviation) air temperature and precipitation were 2.0 
$\pm 0.8{ }^{\circ} \mathrm{C}$ and $676 \pm 206 \mathrm{~mm}$, respectively, across 2008 -2018 (Liu et al. 2021b). A 48-m-high tower was set up at the low-part of the sidewall of a valley (Fig. 1). The vegetation around the flux tower was a 70-year-old temperate deciduous broadleaved forest with $\sim 20 \mathrm{~m}$ high canopy in average (Liu et al. 2021b). The maximum canopy leaf area index estimated by the litterfall collection varied from 5.8 to $6.5 \mathrm{~m}^{2} \mathrm{~m}^{-2}$ during 2012-2018 (Liu et al. 2021a). The major tree species are Betula platyphylla, Ulmus japonica, and Fraxinus mandshurica.

\section{Instrument configuration and flux calculation}

An open-path EC system (LI-7500, Li-Cor Inc., Lincoln, NE, USA; CSAT3, Campbell Scientific Inc., USA) was installed at the $36 \mathrm{~m}$ height to measure the vertical turbulent flux of $\mathrm{CO}_{2}$. The original data were recorded at a frequency of $10 \mathrm{~Hz}$ with a datalogger (CR3000, Campbell Scientific Inc., USA). An 8-level profile of $\mathrm{CO}_{2} / \mathrm{H}_{2} \mathrm{O}$ concentrations $(0.5,2.0,4.0,8.0,16.0,20.0,28.0$, and $36.0 \mathrm{~m}$ above the ground surface) was measured by the AP100 (Campbell Scientific Inc., USA) to calculate the storage flux of $\mathrm{CO}_{2}$ (Wang et al. 2016).

Half-hourly net ecosystem exchange of $\mathrm{CO}_{2}$ (NEE) was calculated as the sum of eddy flux $\left(F_{\mathrm{c}}\right)$ and storage flux $\left(F_{\mathrm{s}}\right)$. The $F_{\mathrm{c}}$ data were processed with the flux measurement standard procedures, including despiking, timelag removing, planar-fit tilt correction, frequency response correction, density effect and surface heating correction, and quality control (Aubinet et al. 2012). The $F_{\mathrm{s}}$ was calculated by the 2-min mean 8 -level profile within each $30 \mathrm{~min}$ to minimize the underestimation of the magnitude of the $F_{\mathrm{s}}$ (Wang et al. 2016). The earlyevening maximum respiration method was used to filter the nighttime NEE (van Gorsel et al. 2009). There were eight large gaps ( $>15$ days) due to instrument malfunction etc.: March 3 to April 21 and July 13 to July 30 in 2010, January 17 to March 20, April 22 to May 11, June11 to June 25, August 11 to August 27, and November 9 to December 11 in 2013; August 27 to October 25 in 2017. The gaps of daytime NEE during growing season months (May-September) was filled by the monthly Michaelis-Menten type light response curve (Falge et al. 2001). The light response curve for September in 2017 cannot be fitted, and the parameters for another year (2018) with similar air temperature to September in 2017 was used to fill the gap. The ecosystem respiration was fitted with moisture-modified empirical temperature-respiration model (Noormets et al. 2008) for the growing season, and with Lloyd-Taylor model (Lloyd and Taylor 1994) for the non-growing season. We extrapolated nighttime respiration into the daytime to estimate the GPP (Liu et al. 2021b; Reichstein et al. 2005). The footprint of $\mathrm{CO}_{2}$ flux was 800-1200 m during the daytime along the valley ( $90 \%$ signal).

\section{Broadband vegetation index calculation}

A net radiometer (CNR1 or CNR4, Kipp \& Zonen, the Netherlands) was installed at the $48 \mathrm{~m}$ height of the tower to measure the incoming and outgoing radiation $\left(\mathrm{W} \mathrm{m} \mathrm{m}^{-2}\right.$ ), including solar (short-wave, $300-2800 \mathrm{~nm}$ ) and long-wave radiation $(4.5-42 \mu \mathrm{m})$. The CNR1 was operated from 2008 to 2015 , and the CNR4 was operated since 2015; The bias of CNR1 relative to CNR4 was removed by a linear model. The incident and reflected photosynthetically active radiation (PAR, 400-700 nm, $\mu \mathrm{mol} \mathrm{m}{ }^{-2} \mathrm{~s}^{-1}$ ) were measured by a pair of light quantum sensors (PQS1 or PARLITE, Kipp \& Zonen, the Netherlands). The footprint of hemispherical radiometers was 176 m radially (90\% signal). The drift of radiometers was calibrated by the manufacturer in 2015. All

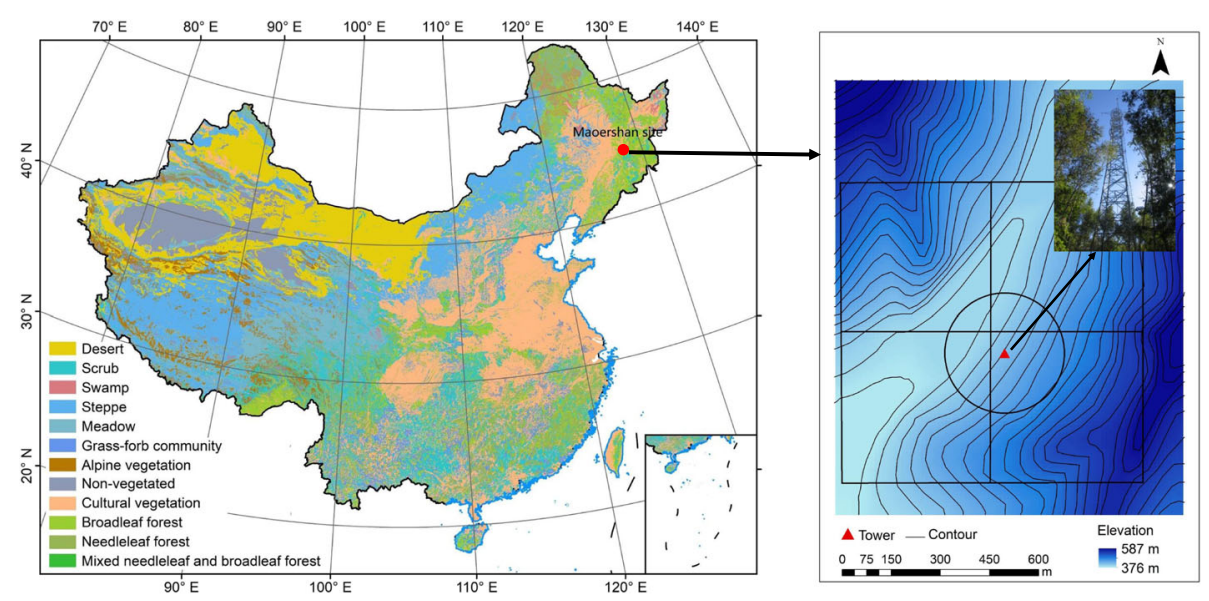

Fig. 1 A map of study area with the location and photo image of eddy-flux tower. The four squares and the circle represent the four pixels of MODIS and the reflective footprint of the radiometers installed on the tower ( $90 \%$ of signal), respectively. The vegetation map of China adopted from Su et al. (2020) 
the radiation data were sampled every $5 \mathrm{~s}$, and averaged every $30 \mathrm{~min}$ and stored in a CR1000 datalogger (Campbell, Scientific, Inc., Logan, UT, USA). We calculated the broadband VIs, i.e., NDVI $\left(\mathrm{NDVI}_{\mathrm{B}}\right)$, EVI $\left(\mathrm{EVI}_{\mathrm{B}}\right)$ and $\mathrm{NIRv}\left(\mathrm{NIRv}_{\mathrm{B}}\right)$ as:

$$
\begin{aligned}
& \mathrm{NDVI}_{\mathrm{B}}=\frac{\mathrm{r}_{\mathrm{NIR}}-\mathrm{r}_{\mathrm{PAR}}}{\mathrm{r}_{\mathrm{NIR}}+\mathrm{r}_{\mathrm{PAR}}} \\
& \mathrm{EVI}_{\mathrm{B}}=\frac{2.5 \times\left(\mathrm{r}_{\mathrm{NIR}}-\mathrm{r}_{\mathrm{PAR}}\right)}{\mathrm{r}_{\mathrm{NIR}}+2.4 \times \mathrm{r}_{\mathrm{PAR}}+1} \\
& \mathrm{NIRv}_{\mathrm{B}}=\mathrm{NDVI}_{\mathrm{B}} \times \mathrm{r}_{\mathrm{NIR}} \\
& \mathrm{r}_{\mathrm{PAR}}=\frac{\mathrm{PAR}_{\text {out }}}{\mathrm{PAR}_{\text {in }}} \\
& \mathrm{r}_{\mathrm{NIR}}=\frac{\mathrm{SOLR}_{\text {out }}-\mathrm{PAR}_{\text {out }}}{\mathrm{SOLR}_{\text {in }}-\mathrm{PAR}_{\text {in }}}
\end{aligned}
$$

where $r_{\text {NIR }}$ and $r_{\text {PAR }}$ are the albedo of near-infrared and photosynthetically active radiation, respectively. $\mathrm{PAR}_{\text {out }}, \mathrm{PAR}_{\text {in }}, \mathrm{SOLR}_{\text {out }}$, and SOLR in are the reflected and incident PAR and solar radiation, respectively. The reflectance of blue band cannot be obtained by the broadband radiometers, we used the two band $\mathrm{EVI}_{\mathrm{B}}$ to substitute for the traditional EVI with blue band (Rocha and Shaver 2009). A moving window approach that assigned the 50th percentile of the values around noon (10:00-14:00 local time) within a 3-d window to the center day was used to smooth the broadband VI time series (Liu et al. 2019a; Sonnentag et al. 2012).

\section{MODIS vegetation index calculation}

The MODIS product of 500-m surface reflectance data (MOD09A1) was obtained from ORNL DAAC (ORNL DAAC 2018; Vermote 2015), which was an 8-d composite by selecting observations with favorable viewing geometry and minimal cloud cover. The MODIS VIs, i.e., NDVI $\left(\mathrm{NDVI}_{\mathrm{M}}\right)$, EVI $\left(\mathrm{EVI}_{\mathrm{M}}\right)$ and $\mathrm{NIRv}\left(\mathrm{NIRv}_{\mathrm{M}}\right)$, were calculated using band 1 (red, 620-670 nm), band 2 (NIR, 841-876 nm), and band 3 (blue, 459-479 $\mathrm{nm}$ ):

$$
\begin{aligned}
& \mathrm{NDVI}_{\mathrm{M}}=\frac{\mathrm{r}_{\mathrm{NIR}}-\mathrm{r}_{\mathrm{RED}}}{\mathrm{r}_{\mathrm{NIR}}+\mathrm{r}_{\mathrm{RED}}} \\
& \mathrm{EVI}_{\mathrm{M}}=\frac{2.5 \times\left(\mathrm{r}_{\mathrm{NIR}}-\mathrm{r}_{\mathrm{RED}}\right)}{\mathrm{r}_{\mathrm{NIR}}+6 \times \mathrm{r}_{\mathrm{RED}}-7.5 \times \mathrm{r}_{\mathrm{BLUE}}+1} \\
& \mathrm{NIRv}_{\mathrm{M}}=\mathrm{NDVI}_{\mathrm{M}} \times \mathrm{r}_{\mathrm{NIR}}
\end{aligned}
$$

where $r_{N I R}, r_{\text {RED }}$ and $r_{\text {BLUE }}$ are the reflectance of nearinfrared, red and blue bands, respectively. The quality control of MOD09A1 removed all data that were flagged as cloud, cloud shadow or cirrus cloud, and the view zenith angle was constrained to $<60^{\circ}$.

\section{Phenology, summer peak and vegetation index "production" estimation}

A double-logistic model (Eq. 9) was used to fit the time series of GPP and VI (Fig. 2) and define the start and end of growing season (SOS and EOS). The SOS and EOS of GPP ( $\mathrm{SOS}_{\mathrm{GPP}}$ and $\left.\mathrm{EOS}_{\mathrm{GPP}}\right)$ were defined as the $25 \%$ of the maximum daily GPP in spring and autumn, respectively, because of the highest correlation with the IAV in GPP (Liu et al. 2021b). Considering the seasonal asynchrony between VI and GPP, the SOS and EOS of VI $\left(\mathrm{SOS}_{\mathrm{VI}}\right.$ and $\left.\mathrm{EOS}_{\mathrm{VI}}\right)$ were defined from $10 \%$ to $50 \%$ of amplitude at $5 \%$ intervals to compare with $\mathrm{SOS}_{\mathrm{GPP}}$ and $\mathrm{EOS}_{\mathrm{GPP}}$. The growing season lengths of GPP and VI were calculated as the number of days from SOS to EOS. Additionally, the inflection point of curvature change was also used to test the relationship between phenology parameters defined by VI and GPP. Because the relationships between the VI and GPP phenology extracted from the change of curvature method, and between integral VI and annual GPP were much weaker than that for the threshold-method (Figs. A1-2), we then only focused on the threshold method.

$$
\mathrm{f}(\mathrm{t})=\mathrm{a}+\frac{\mathrm{b}}{1+\mathrm{e}^{(\mathrm{c}-\mathrm{t}) / \mathrm{d}}}-\frac{\mathrm{g}}{1+\mathrm{e}^{(\mathrm{e}-\mathrm{t}) / \mathrm{f}}}
$$

where $a$ is the background GPP or VI, $b$ and $g$ are the amplitudes of GPP or VI in spring and autumn, respectively; $c$ and $e$ are the midpoints for spring and autumn (day of year), respectively; $d$ and $f$ are the transitions curvature parameters.

It has been reported that the summer peak of GPP dominated the IAV in GPP across the northern hemispheric ecosystems (Xia et al. 2015; Zhou et al. 2016; Zhou et al. 2017), thus the peaks of VI were also compared with that of GPP. The integral and mean VIs, the proxies of "production" (Zhou 2020), were calculated as accumulating and averaging the fitted VI values across the growing season defined by different thresholds.

\section{Testing the consistency between vegetation index and GPP}

The $R^{2}$ of linear regression was performed to assess the consistency of long-term trends between VI and GPP, and the mean bias and absolute deviation (MAD) were used to assess the differences in absolute date between VI and GPP phenology. A positive (negative) bias of VI phenology means that it is later (earlier) than GPP phenology.

$$
\text { Bias }=\frac{\sum_{i=1}^{\mathrm{N}}(\text { VI phenology-GPP phenology })}{N}
$$



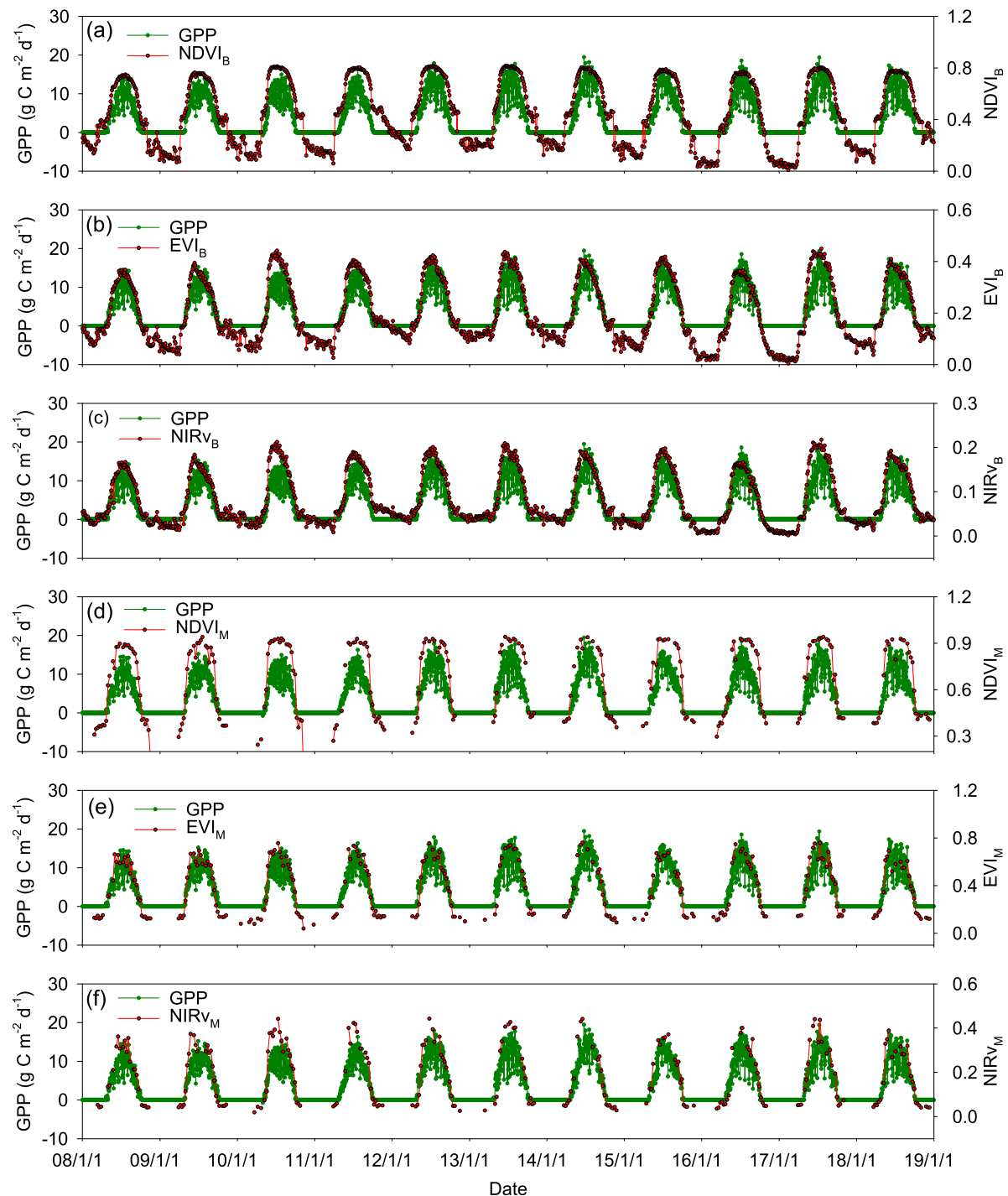

Fig. 2 Seasonalities of gross primary production and vegetation indices during 2008-2018. NDVIB: broadband normalized difference vegetation index, $\mathrm{EVI}_{\mathrm{B}}$ : broadband enhanced vegetation index, $\mathrm{NIRV}_{\mathrm{B}}$ : broadband near-infrared albedo of vegetation, NDVI $\mathrm{M}$ : MODIS normalized difference vegetation index, $\mathrm{EVI}_{\mathrm{M}}$ : MODIS enhanced vegetation index, $\mathrm{NIRV}_{\mathrm{M}}$ : MODIS near-infrared reflectance of vegetation

$$
\mathrm{MAD}=\frac{\sum_{i=1}^{N} \mid V I \text { phenology-GPP phenology } \mid}{N}
$$

where $N$ is the number of years (11 in this study). The relative importance of summer peak and growing season length to the IAV of "production" (GPP or integral VI) was quantified with a multiple linear regression analysis (Grömping 2006) based on variance decomposition, and then was compared between integral VI and GPP.

\section{Results}

Relationships between vegetation indices and annual GPP The relationship between growing-season integral VI and annual GPP was markedly affected by VI type but not the definition threshold of VI magnitude (Fig. 3). Among the six tested VIs, the integral $\mathrm{EVI}_{\mathrm{M}}$ performed best for tracking the IAV in GPP, with a narrow range of $R^{2}(0.60-0.67)$, followed by the integral $\operatorname{NIRv}_{M}\left(R^{2}=\right.$ $0.52-0.63)$. The integral $\mathrm{NDVI}_{\mathrm{B}}$ defined by the nine thresholds explained $44 \%-60 \%$ of the IAV in GPP, and the relationships between integral $\mathrm{NDVI}_{\mathrm{B}}$ defined from $30 \%$ to $50 \%$ threshold and annual GPP were highly conservative $\left(R^{2}=0.58-0.60\right)$. Nevertheless, the integral $\mathrm{NDVI}_{\mathrm{M}}$ only explained $23 \%-39 \%$ of the change of annual 

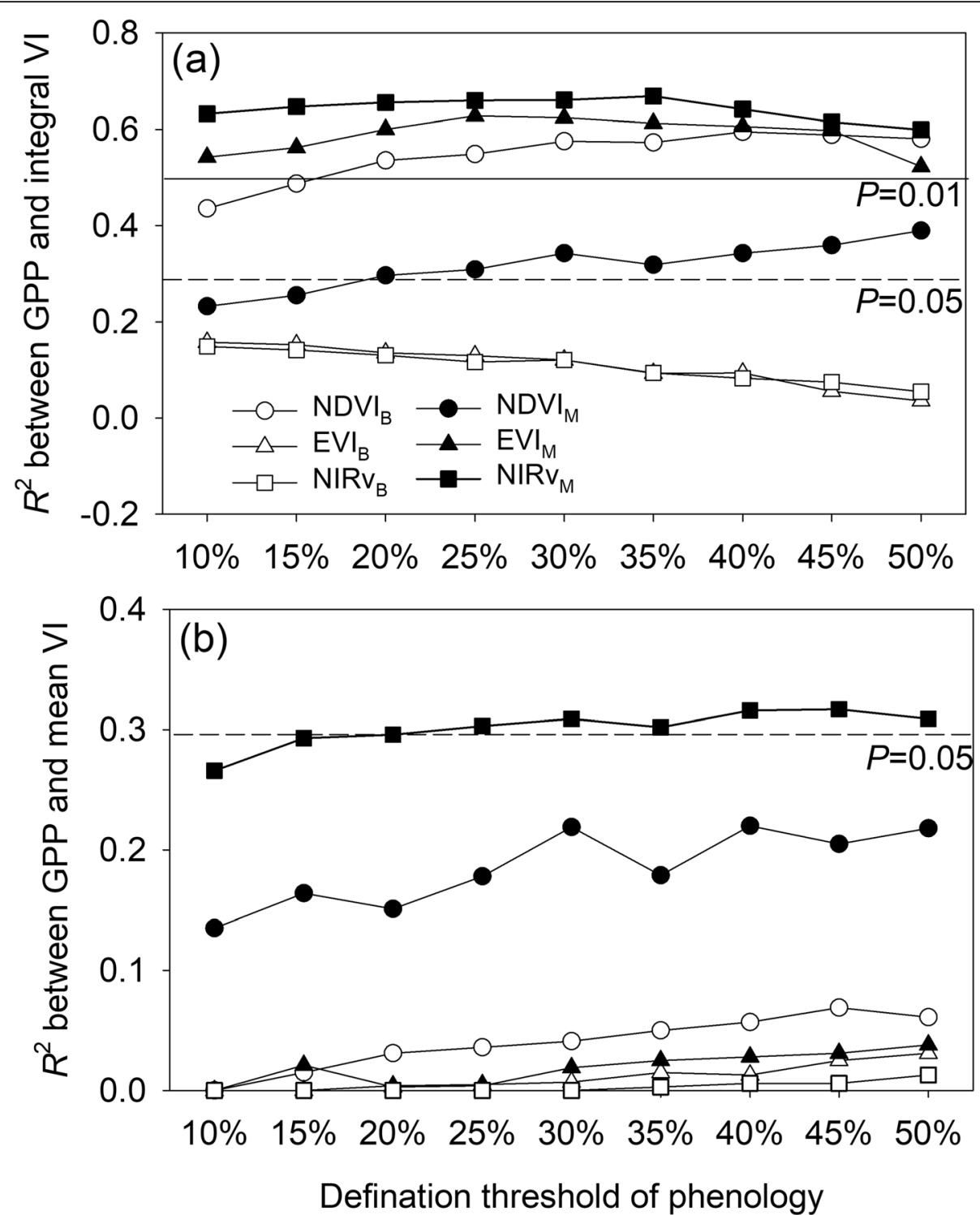

Fig. 3 Determination coefficient $\left(R^{2}\right)$ of the regression of annual gross primary production (GPP) against the integral vegetation indices (VIs) or mean VIs for the growing-season defined by different thresholds. NDVI $I_{B}$ : broadband normalized difference vegetation index, EVI : broadband enhanced vegetation index, $\mathrm{NIRV}_{\mathrm{B}}$ : broadband near-infrared albedo of vegetation, $\mathrm{NDVI}_{\mathrm{M}}$ : MODIS normalized difference vegetation index, $\mathrm{EVI}_{\mathrm{M}}$ : MODIS enhanced vegetation index, NIRV $v_{M}$ : MODIS near-infrared reflectance of vegetation

GPP, while the integral $\mathrm{EVI}_{\mathrm{B}}$ and $\mathrm{NIRv}_{\mathrm{B}}$ could not track the IAV in GPP $(P>0.05)$. The growing-season mean VIs performed generally poorly compared with their integrations (Fig. 3b). Moreover, defining the growing season by combining different thresholds of spring and autumn phenology did not improve the $R^{2}$ (Fig. A3).

Partitioning the annul GPP into growing season length and GPP peak, the IAV in GPP was predominated by GPP peak (69\%), followed by growing season length (19\%). Using the VIs integrated across the growing season defined by the optimal thresholds as a proxy of GPP, only the $\mathrm{NIRv}_{\mathrm{M}}$ reflected the contributions of summer peak (69\%) and growing season length (14\%) to the "production" accurately. However, the other VIs overestimated or underestimated the contributions of summer peak and growing season length to "production" (Fig. 4).

\section{Comparisons of phenological metrics estimated by vegetation indices and GPP}

The relationships between VI and GPP phenology changed with VI type, definition threshold, and season (Fig. 5). All the SOS and EOS defined by GPP and VI had no advanced or delayed trends during 2008-2018 (Figs. A4 and A5). In spring, the broadband VIs performed better than MODIS VIs in capturing the IAV of $\mathrm{SOS}_{\mathrm{GPP}}$, with the corresponding $R^{2}$ of $0.20-0.60$ and $0-0.35$. Among 


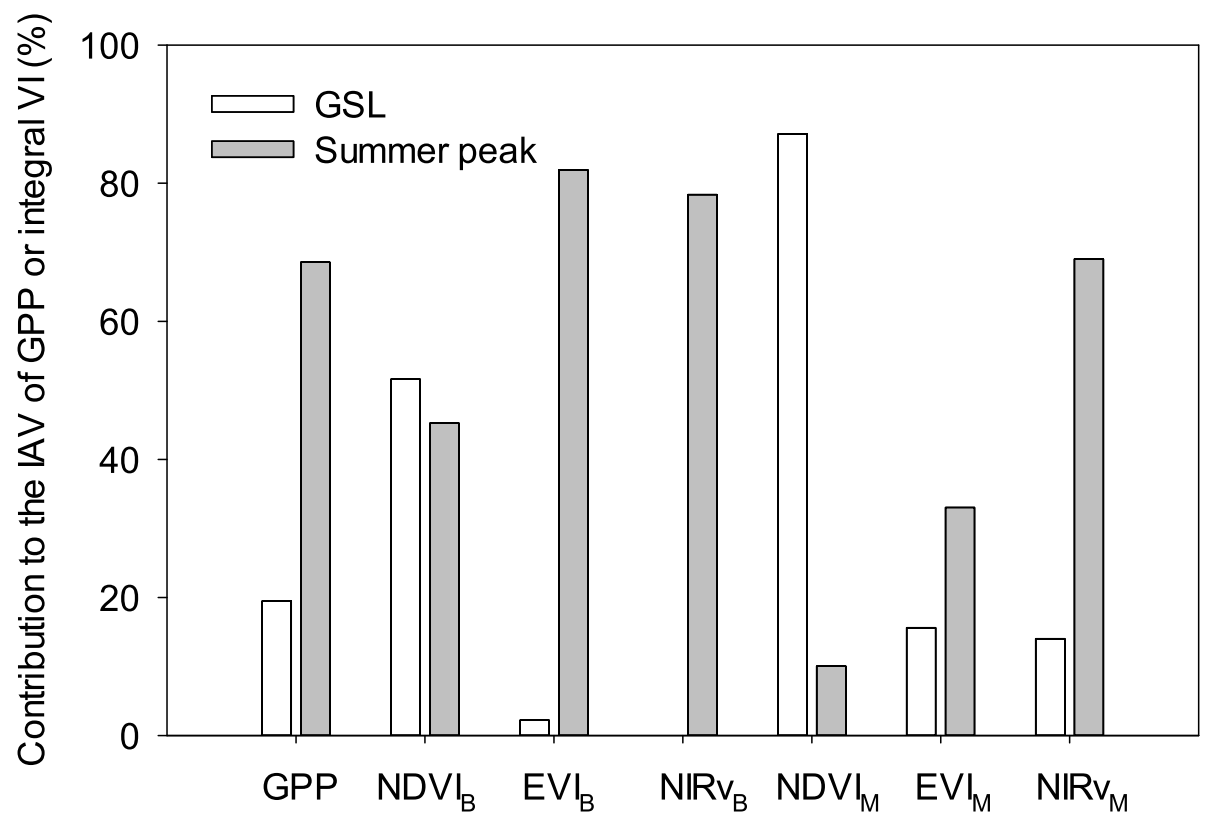

Fig. 4 Relative importance of the growing season length (GSL) and summer peak to the interannual variation in gross primary production (GPP)

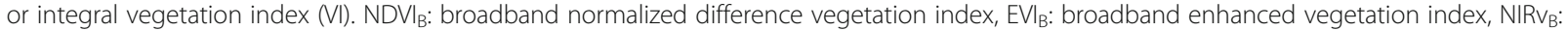
broadband near-infrared albedo of vegetation, $\mathrm{NDV}_{\mathrm{M}}$ : MODIS normalized difference vegetation index, EVI $\mathrm{M}_{\mathrm{M}}$ MODIS enhanced vegetation index, $N I R v_{M}$ : MODIS near-infrared reflectance of vegetation

the tested thresholds for each broadband VI, the $45 \%$ of $\mathrm{NDVI}_{\mathrm{B}}$ amplitude, $35 \%$ of $\mathrm{EVI}_{\mathrm{B}}$ amplitude, and $50 \%$ of $\mathrm{NIRv}_{\mathrm{B}}$ amplitude showed the largest $R^{2}(0.46,0.60$, and 0.54 ), with the positive biases of 5,4 , and $9 \mathrm{~d}$, respectively. However, the SOS derived by the three MODIS VIs was poorly consistent with $\mathrm{SOS}_{\mathrm{GPP}}$, regardless of the threshold.

In autumn, the relationships between $\mathrm{EOS}_{\mathrm{VI}}$ and $E_{\text {GPP }}$ were relatively insensitive to the definition threshold of EOS ${ }_{\mathrm{VI}}$. The EOS of MODIS VIs generally had a higher $R^{2}$ than that of broadband VIs $(0.1-0.73$ versus $0-0.76)$. The $35 \%$ of $\mathrm{NDVI}_{\mathrm{M}}$ amplitude $\left(R^{2}=\right.$ 0.73 , bias $=6 \mathrm{~d})$ and the $30 \%$ of $\mathrm{NDVI}_{\mathrm{B}}$ amplitude $\left(R^{2}=\right.$ 0.70 , bias $=7 \mathrm{~d}$ ) had the tightest relationship with $E_{\text {GPP }}$ for the MODIS and broadband VIs, respectively. Although the $15 \%$ of $\mathrm{EVI}_{\mathrm{B}}$ amplitude and the $10 \%$ of $\mathrm{NIRv}_{\mathrm{B}}$ amplitude also had high $R^{2}(0.64$ and 0.76$)$, the biases were very large (15 and $28 \mathrm{~d})$.

\section{Comparisons of summer peaks of vegetation indices and GPP}

The peaks of GPP and $\mathrm{NDVI}_{\mathrm{M}}$ significantly increased by a rate of $0.30 \mathrm{~g} \mathrm{C} \mathrm{m}^{-2} \mathrm{yr}^{-2}(2 \%)$ and $0.004 \mathrm{yr}^{-1}(0.4 \%)$, respectively, whereas the peaks of the other tested VIs had no significant trends (Fig. 6). Surprisingly, the peaks of VIs had very weak relationships with GPP peak (Fig. 7). The peaks of $\mathrm{NIRv}_{\mathrm{M}}$ and $\mathrm{NDVI}_{\mathrm{M}}$ were weakly consistent with GPP peak across the 11 years $\left(R^{2}=0.39\right.$ and 0.31 , respectively), while the peaks of the other VIs could not track the IAV in GPP peak $\left(R^{2}<0.01\right)$.

\section{Discussion}

Tracking the variation in annual GPP by vegetation index Our results indicated that the integral $\mathrm{NIRv}_{M}$ was a robust proxy of the IAV of GPP among the six tested VIs, which was inaccordance with previous studies (Baldocchi et al. 2020; Wang et al. 2021). However, the moderate tight relationship between $\mathrm{NDVI}_{\mathrm{M}}$ and GPP did not support using the integral $\mathrm{NDVI}_{\mathrm{M}}$ as the proxy of GPP (e.g. Verma et al. 2014; Wylie et al. 2003; Zhou 2020). Changing the definition threshold of VI growing-season had little influence on the relationship between the integral VI and GPP at our site, because the IAV of GPP was predominated by GPP peak (which was poorly reflected by the tested VIs) rather than GPP phenology (Fig. 5; Xia et al. 2015; Zhou et al. 2016). However, for those sites with a larger contribution of GPP phenology than GPP peak, the definition threshold of growing season may be of significance.

The discrepancies in the IAV of the integral VI and GPP may be attributed to the differences in their seasonal trajectories. First, the weak ability of VI for charactering the summer peak (Fig. 7) reduced the relationship between the integral VI and GPP (Shi et al. 2017). Second, the rapid change of species composition may alter the VI-GPP relationship because of the species-specific optical properties (Mbow et al. 2013; Musavi et al. 


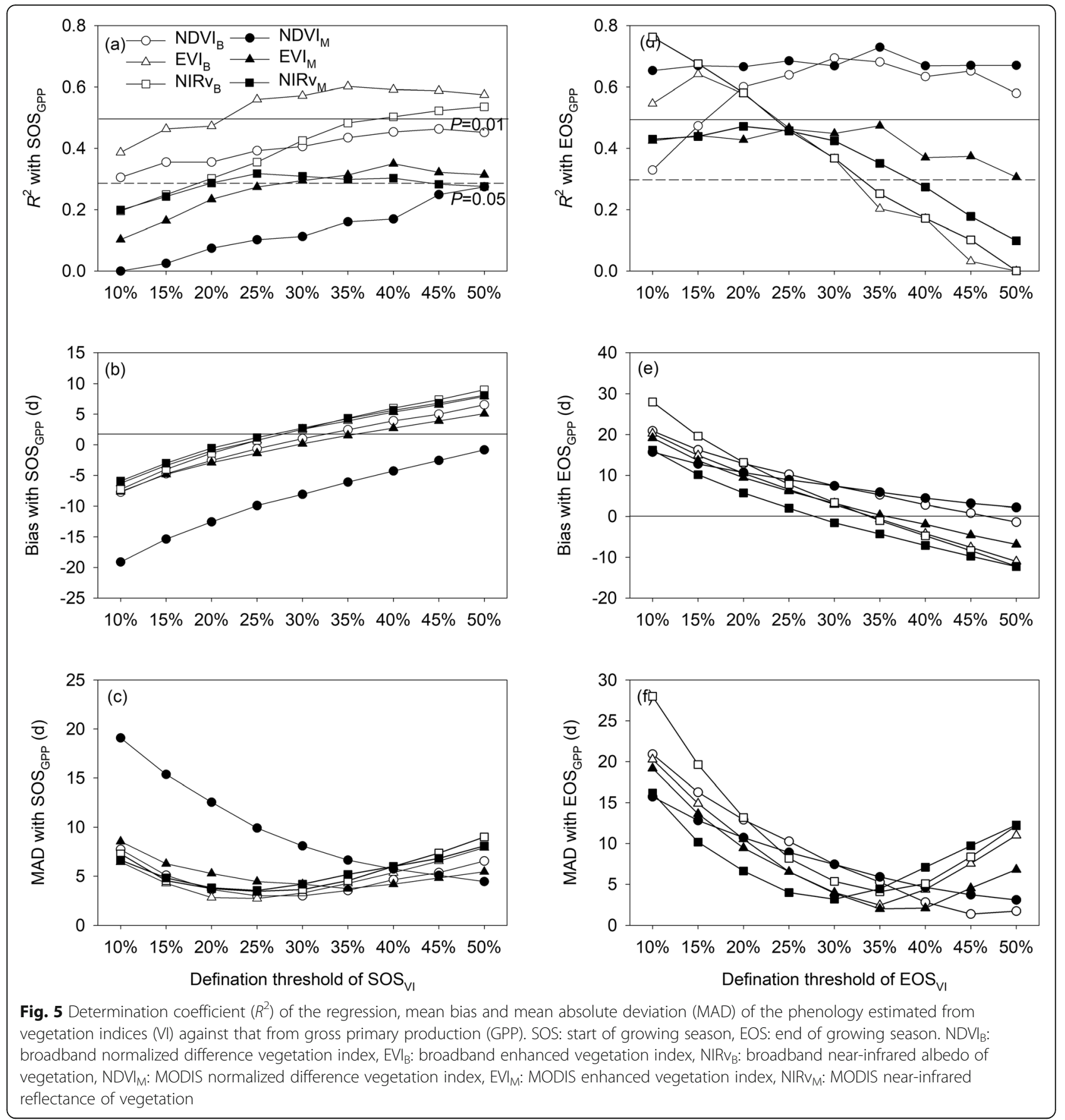

2017). Over the 11 years, the litterfall mass of the pioneer species $B$. platyphylla decreased by $17 \%$, while that of the two mid-successional species, $U$. japonica and $F$. mandshurica, increased by $28 \%$ and $24 \%$, respectively (Calculated from Sun et al. 2021). Third, the photosynthetic rate was sensitive to environmental factors, so the GPP was not always high when the VI was high (Nagai et al. 2010). Additionally, the methods of gap filling and flux partitioning (Falge et al. 2001; Lasslop et al. 2010; Reichstein et al. 2005; Tramontana et al. 2020) may also introduce uncertainties in the VI-GPP relationship. Finally, improving the cloud screening and considering the fraction of diffuse radiation is imperative for accurately modeling GPP (Badgley et al. 2019; Huang et al. 2019). The solar-induced chlorophyll fluorescence (SIF) can improve the accuracy of GPP retrievals ( $\mathrm{Li}$ and Xiao 2020; Lu et al. 2018; Yang et al. 2017). However, the SIF products are noisy and long-term SIF products are lacking, VIs are still the most widely used indicator of GPP (Lu et al. 2018). 

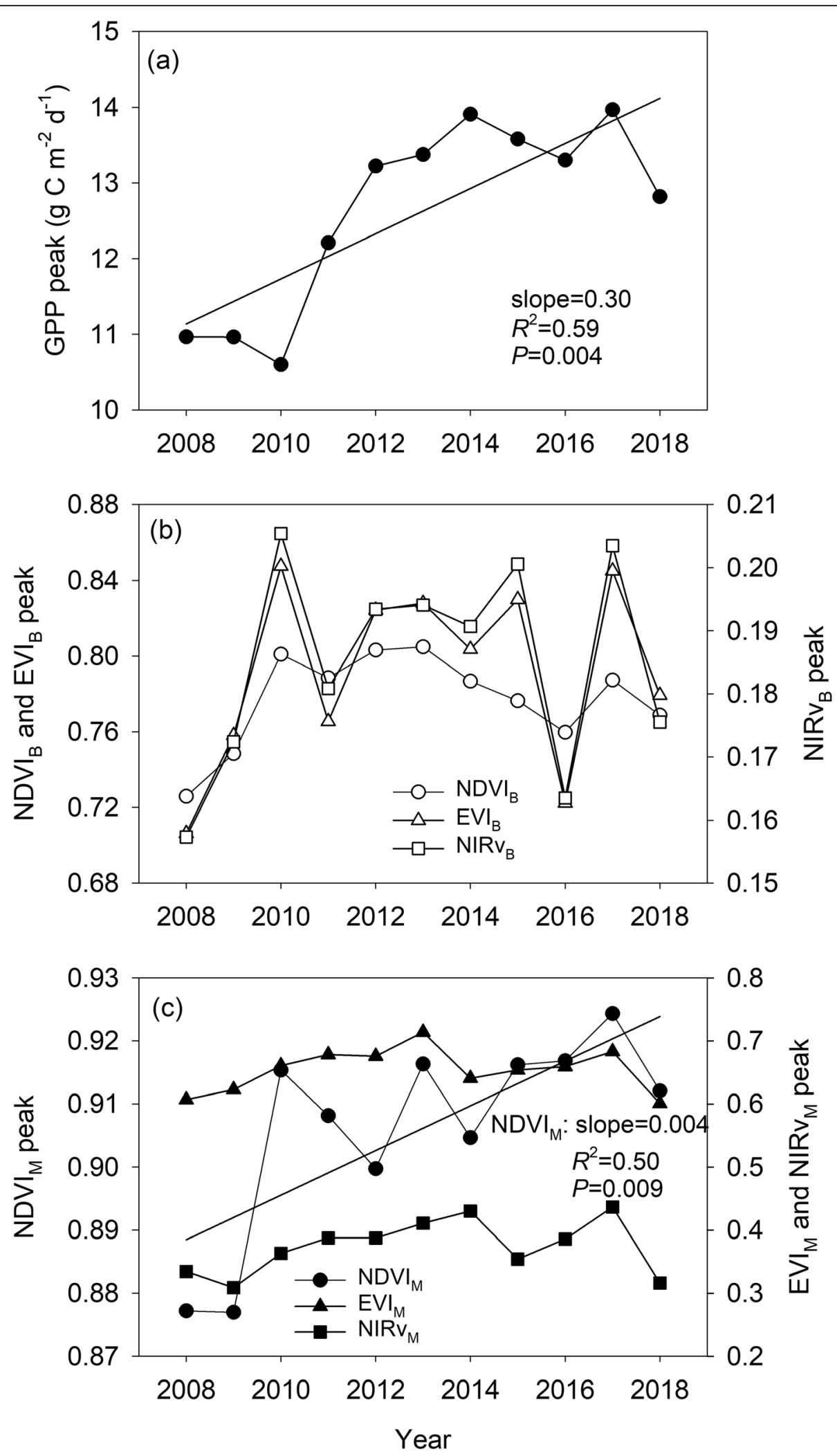

Fig. 6 Interannual variation in the summer peaks of gross primary production (GPP) and vegetation indices. NDVI: broadband normalized difference vegetation index, $\mathrm{EV}_{\mathrm{B}}$ : broadband enhanced vegetation index, $\mathrm{NIRV}_{\mathrm{B}}$ : broadband near-infrared albedo of vegetation, NDVIM: MODIS

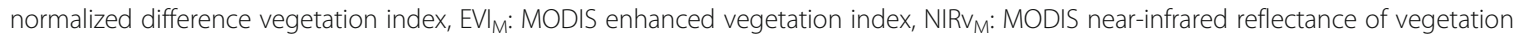



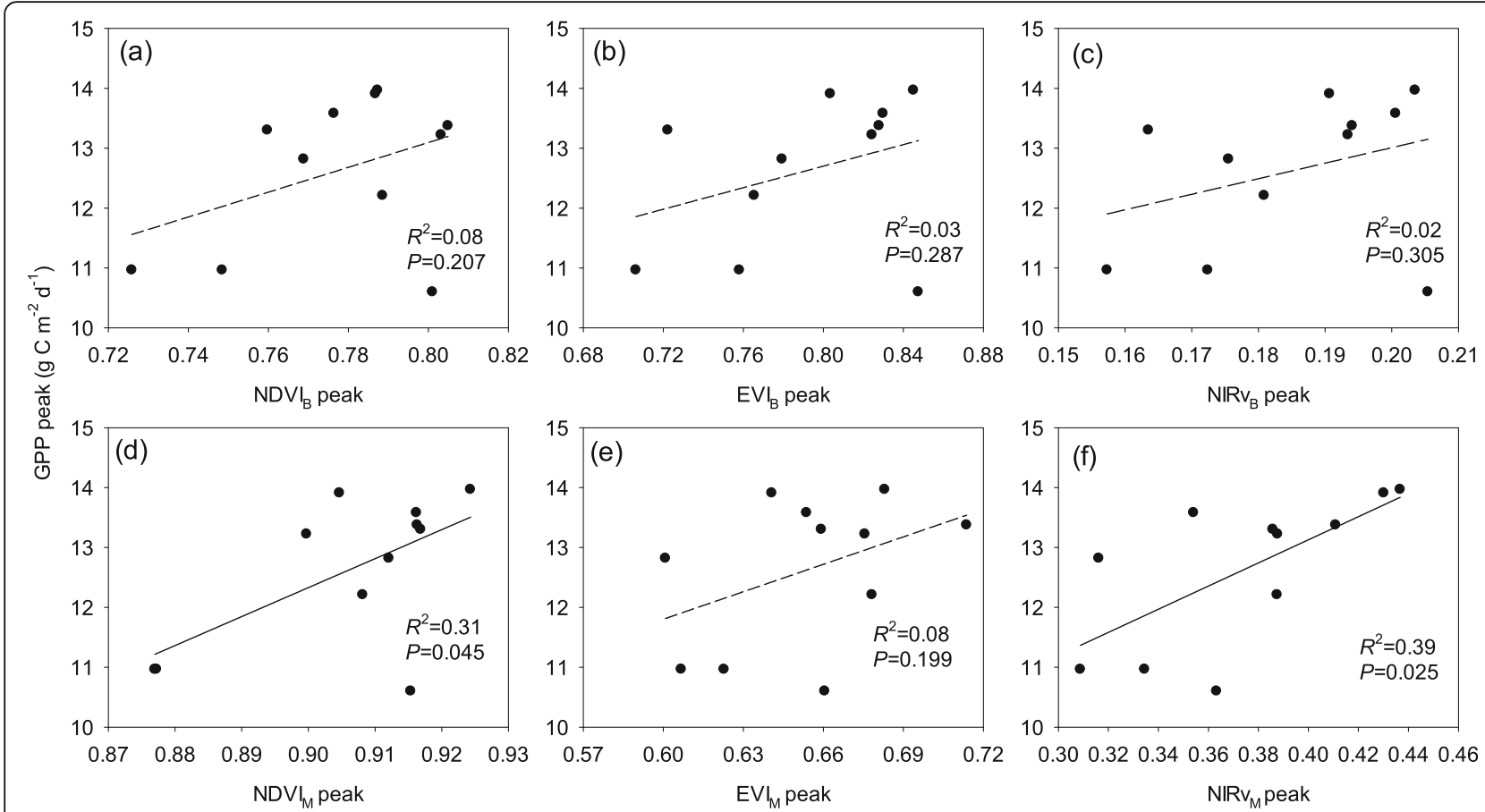

Fig. 7 Relationships between the summer peaks of gross primary production (GPP) and vegetation indices. NDVI ${ }_{B}$ : broadband normalized difference vegetation index, $\mathrm{EVI}_{\mathrm{B}}$ : broadband enhance vegetation index, $\mathrm{NIRV}_{\mathrm{B}}$ : broadband near-infrared albedo of vegetation, $\mathrm{NDV} \mathrm{I}_{\mathrm{M}}$ : MODIS

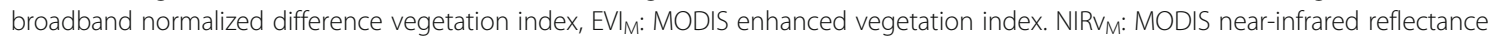
of vegetation

The difference in spatial scale can also explain the mismatch between integral VI and GPP. The field of view of radiometers was constant, which was determined by the installation height. The limited height of tower resulted in a small viewing area (the radius of viewing field was $176 \mathrm{~m}$ ). The EC footprint varied 10-100 times of the measurements height with atmospheric stability, wind speed, etc. (Schmid 2002). Marcolla and Cescatti (2018) suggested that radiometers should be taken about 6-15 times higher than turbulent flux ones, which was difficult to achieve. The four MODIS pixels matched better with EC footprint than the radiometers, but it was impossible to match completely. Additionally, the uncertainty caused by mixed-signals of MODIS is also a potential reason for the difference in MODIS VI and GPP by EC.

\section{Characterizing the GPP phenology and summer peak by vegetation index}

The six tested VIs had different abilities in capturing the IAV of $\mathrm{SOS}_{\mathrm{GPP}}$ and $\mathrm{EOS}_{\mathrm{GPP}}$, which was consistent with previous studies (e.g. D'Odorico et al. 2015; Gonsamo et al. 2012; Zhao et al. 2020). In spring, the broadband VIs outperformed the MODIS VIs. This may be a result of the high uncertainty of SOS estimations by the MODIS VIs time series with a coarse temporal resolution and cloud contamination, since the phenology diverged between overstory and understory at our site (Liu et al. 2019b). Conversely, in autumn with more sunny days, the narrow band MODIS VIs were more sensitive to the changes of vegetation features than broadband VIs during leaf senescence period (Elvidge and Chen 1995). Among the three broadband VIs, the $\mathrm{NDVI}_{\mathrm{B}}$ was sensitive to background influences, thus was less satisfactory than $\mathrm{EVI}_{\mathrm{B}}$ and $\mathrm{NIRv}_{\mathrm{B}}$ (Chang et al. 2019; Yin et al. 2020). Contrary to the spring, the NDVI performed better than EVI and NIRv for both broadband and MODIS VIs in autumn. The low solar zenith angle in autumn at our mid-latitudinal site may introduce uncertainties for EVI (Sesnie et al. 2012).

The choice of threshold had little effect on the general trend of phenology (Figs. A4-5; Keenan et al. 2014), but changed both the relationships and absolute differences between VI and GPP phenology over the 11 years. In physiology, the mismatch between VI and GPP phenology is mainly attributed to the time lag between canopy greenness and C uptake. The VI (canopy greenness) generally occurred ahead of GPP in spring and persisted after cessation of GPP in autumn (Lu et al. 2018; Shen et al. 2014). Significant mismatch existed between VI and GPP phenology even though they had strong relationship spatiotemporally (across site-years) in most previous studies, partly because they used the same inflection point to define the VI and GPP phenology. For example, the 
SOS $_{\text {EVIM }}$ defined by the change of curvature was $10-\mathrm{d}$ earlier than $\mathrm{SOS}_{\mathrm{GPP}}$ across deciduous broadleaved forests of Ameriflux sites (Gonsamo et al. 2012; Shen et al. 2014). The $\mathrm{NDVI}_{\mathrm{M}^{-}}, \mathrm{EVI}_{\mathrm{M}^{-}}$, and $\mathrm{NIRv}_{\mathrm{M}^{-}}$-derived EOSs defined by $20 \%$ threshold were later than $\mathrm{EOS}_{\mathrm{GPP}}$ by 23,16 , and $15 \mathrm{~d}$, respectively, across the 19 tested deciduous broadleaf forests (Yin et al. 2020). Changing the definition threshold of VI reduced the mismatch between VI and GPP phenology (Fig. 5). Therefore, we recommend using the threshold-method to define the VI and GPP phenology. First, the relationship between VI and GPP phenology by the threshold-method was higher than that by the change of curvature method (Figs. 5 and A2), which was partly consistent with the situation of NDVI (D'Odorico et al. 2015). Second, the curvature-method may fail to extract SOS and EOS when the curvature of the fitted curve do not have inflection point (Shen et al. 2014). Despite of the hysteresis in seasonal VI and GPP patterns, using appropriate definition threshold of VI magnitude can effectively estimate the GPP phenology. Jointly considering the $R^{2}$, bias and MAD, we recommend that using the $25 \%-35 \%$ of $\mathrm{EVI}_{\mathrm{B}}$ amplitude to track the $\mathrm{SOS}_{\mathrm{GPP}}$, and using $50 \%$ amplitude of $\mathrm{NDVI}_{\mathrm{B}}$ and $\mathrm{NDVI}_{\mathrm{M}}$ to capture the $\mathrm{EOS}_{\mathrm{GPP}}$.

However, the peaks of the six tested VIs could not characterize the IAV of the GPP peak. Although the peaks of $\mathrm{NDVI}_{M}$ and $\mathrm{NIRv}_{\mathrm{M}}$ were significantly correlated with GPP peak, they could not capture the long-term increasing trend. There are a few reasons for the failure of VI peak in indicating the GPP peak. First, the VI (particularly the NDVI) saturates in summer, thus it only detects the sunlit leaves of overstory but not the shaded leavers of overstory and understory (D'Odorico et al. 2015). Although the $\mathrm{NIRv}_{M}$ is sensitive at high leaf area index, the cloud contamination is still a problem for satellite data (Badgley et al. 2019), particularly for our site usually with a wet summer (Liu et al. 2021b). Second, the photosynthetic capability of vegetation may vary with environmental drivers even when vegetation spectral properties were similar (Zhao et al. 2020). These results indicate the peaks of VIs should be precautionarily used as proxies of the IAV of the peak of ecosystem activity or GPP.

As far as we know, this is the first comprehensive study to investigate the abilities of VIs in capturing the IAV of the phenology, summer peak and annual flux of GPP. These results may be not universal, but has great implications for future remote sensing studies on GPP. These thresholds can be tested using a larger dataset, for example, with the dataset of FLUXNET (Baldocchi et al. 2001).

\section{Conclusion}

The abilities of tower-based broadband and MODIS VIs on tracking the IAV of GPP were comprehensively evaluated in the temperate deciduous forest. The growing-season integral $\mathrm{NIRv}_{\mathrm{M}}$ best represented the IAV in annual flux of GPP, and its performance was insensitive to the threshold of magnitude. In contrast, both VI type and threshold of magnitude were important for accurately modeling the GPP phenology, of which the $35 \%$ of $\mathrm{EVI}_{\mathrm{B}}$ amplitude in spring and $50 \%$ of $\mathrm{NDVI}_{\mathrm{M}}$ amplitude in autumn performed best. The peaks of the six tested VIs could not reflect the IAV in GPP peak. We concluded that using appropriate VI (and thresholds of magnitude) could improve the ability of monitoring annual GPP (and GPP phenology) in deciduous forests.

\section{Abbreviations \\ GPP: GPP Gross primary production; IAV: Interannual variation; VI: Vegetation index; NDVI: Normalized difference vegetation index; EVI: Enhanced vegetation index; NIRV: Near-infrared reflectance of vegetation; SOS: Start of growing season; EOS: End of growing season; EC: Eddy covariance}

\section{Supplementary Information}

The online version contains supplementary material available at https://doi. org/10.1186/s13717-021-00324-2.

\begin{abstract}
Additional file 1: Fig. A1 Regressions between annual gross primary production (GPP) and the integral or mean vegetation indices for the growing-season defined by the rate of change in curvature. Fig. A2 Comparisons of phenology metrics extracted from vegetation indices and gross primary production defined by the rate of change in the curvature. Fig. A3 Determination coefficients $\left(R^{2}\right)$ of the regression of annual gross primary production (GPP) against the integral vegetation indices (VIs) or mean Vls for the growing-season defined by combining the spring and autumn phenology of different thresholds. Fig. A4 Interannual variation in spring and autumn phenology based on broadband vegetation indices defined by nine thresholds. Fig. A5 Interannual variation in spring and autumn phenology based on MODIS vegetation indices defined by nine thresholds.
\end{abstract}

\section{Acknowledgements}

We thank many colleagues and students for assistance in the setup and maintenance of the flux tower, and the editor and three anonymous reviewers for their valuable comments on the manuscript.

\section{Authors' contributions}

XW and CW conceived the ideas and designed the study. FL and XC collected and analyzed the data, and FL led the writing of the first draft of the manuscript. All authors contributed to revising the manuscript and approved the final manuscript.

\section{Funding}

This work was supported by the National Science and Technology Support Program of China (2011BAD37B01), the Fundamental Research Funds for the Central Universities (2572019BA01 and 2572019CP07), and the Program for Changjiang Scholars and Innovative Research Team in University (IRT_15R09).

\section{Availability of data and materials}

Please contact the author for data requests.

\section{Declarations}

Ethics approval and consent to participate Not applicable.

Consent for publication

Not applicable. 


\section{Competing interests}

The authors declare that they have no competing interests.

Received: 17 January 2021 Accepted: 18 June 2021 Published online: 11 July 2021

\section{References}

Ahlström A, Raupach M, Schurgers G, Smith B, Arneth A, Jung M, Reichstein M, Canadell J, Friedlingstein P, Jain A, Kato E, Poulter B, Sitch S, Stocker B, Viovy N, Wang Y, Wiltshire A, Zaehle S, Zeng N (2015) The dominant role of semiarid ecosystems in the trend and variability of the land $\mathrm{CO}_{2}$ sink. Science 348(6237):895-899. https://doi.org/10.1126/science.aaa1668

Aubinet M, Vesala T, Papale D (2012) Eddy covariance: A practical guide to measurement and data analysis. Springer. https://doi.org/10.1007/978-94007-2351-1

Badgley G, Field C, Berry J (2017) Canopy near-infrared reflectance and terrestrial photosynthesis. Sci Adv 3(3):e1602244. https://doi.org/10.1126/sciadv.1602244

Badgley G, Anderegg LDL, Berry JA, Field CB (2019) Terrestrial gross primary production: Using NIR to scale from site to globe. Glob Chang Biol 25(11): 3731-3740. https://doi.org/10.1111/gcb.14729

Baldocchi DD (2020) How eddy covariance flux measurements have contributed to our understanding of Global Change Biology. Glob Chang Biol 26:242-260

Baldocchi D, Falge E, Gu L, Olson R, Hollinger D, Running S, Anthoni P, Bernhofer C, Davis K, Evans R, Fuentes J, Goldstein A, Katul G, Law B, Lee X, Malhi Y, Meyers T, Munger W, Oechel W, Paw U, K.T., Pilegaard K, Schmid HP, Valentini R, Verma S, Vesala T, Wilson K, Wofsy S (2001) FLUXNET: A new tool to study the temporal and spatial variability of ecosystem-scale carbon dioxide, water vapor, and energy flux densities. Bull Am Meteorol Soc 82(11): 2415-2434. https://doi.org/10.1175/1520-0477(2001)082<2415:FANTTS>2.3. $\mathrm{CO} ; 2$

Baldocchi D, Chu H, Reichstein M (2018) Inter-annual variability of net and gross ecosystem carbon fluxes: A review. Agric For Meteorol 249:520-533. https:// doi.org/10.1016/j.agrformet.2017.05.015

Baldocchi DD, Ryu Y, Dechant B, Eichelmann E, Hemes K, Ma S, Sanchez CR, Shortt R, Szutu D, Valach A, Verfaillie J, Badgley G, Zeng Y, Berry JA (2020) Outgoing near-infrared radiation from vegetation scales with canopy photosynthesis across a spectrum of function, structure, physiological capacity, and weather. J Geophys Res Biogeosci 125:e2019JG005534

Balzarolo M, Penuelas J, Veroustraete F (2019) Influence of landscape heterogeneity and spatial resolution in multi-temporal in situ and MODIS NDVI data proxies for seasonal GPP dynamics. Remote Sens 11(14):1656. https://doi.org/10.3390/rs11141656

Beer C, Reichstein M, Tomelleri E, Ciais P, Jung M, Carvalhais N, Rodenbeck C, Arain MA, Baldocchi DD, Bonan GB (2010) Terrestrial gross carbon dioxide uptake: Global distribution and covariation with climate. Science 329(5993): 834-838. https://doi.org/10.1126/science.1184984

Chang Q, Xiao X, Jiao W, Wu X, Doughty RB, Wang J, Du L, Zou Z, Qin Y (2019) Assessing consistency of spring phenology of snow-covered forests as estimated by vegetation indices, gross primary production, and solarinduced chlorophyll fluorescence. Agric For Meteorol 275:305-316. https:// doi.org/10.1016/j.agrformet.2019.06.002

D'Odorico P, Gonsamo A, Gough CM, Bohrer G, Morison JIL, Wilkinson M, Hanson PJ, Gianelle D, Fuentes JD, Buchmann N (2015) The match and mismatch between photosynthesis and land surface phenology of deciduous forests. Agric For Meteorol 214:25-38

ORNL DAAC (2018) MODIS and VIIRS Land Products Global Subsetting and Visualization Tool. ORNL DAAC, Oak Ridge, Tennessee, USA. Accessed June 07, 2019. Subset obtained for MCD43A4 product at 45.42N,127.67E, time period: 2000-02-24 to 2019-05-24, and subset size: $2.5 \times 2.5 \mathrm{~km}$. https://doi. org/10.3334/ORNLDAAC/1379

Elvidge CD, Chen Z (1995) Comparison of broad-band and narrow-band red and near-infrared vegetation indices. Remote Sens Environ 54(1):38-48. https:// doi.org/10.1016/0034-4257(95)00132-K

Falge E, Baldocchi D, Olson R, Anthoni P, Aubinet M, Bernhofer C, Burba G, Ceulemans R, Clement R, Dolman H (2001) Gap filling strategies for defensible annual sums of net ecosystem exchange. Agric For Meteorol 107(1):43-69. https://doi.org/10.1016/S0168-1923(00)00225-2

Gonsamo A, Chen JM, Price DA, Kurz WA, Wu C (2012) Land surface phenology from optical satellite measurement and $\mathrm{CO}_{2}$ eddy covariance technique. J Geophys Res 117:G03032 van Gorsel E, Delpierre N, Leuning R, Black A, Munger JW, Wofsy S, Aubinet M, Feigenwinter C, Beringer J, Bonal D (2009) Estimating nocturnal ecosystem respiration from the vertical turbulent flux and change in storage of $\mathrm{CO}_{2}$. Agric For Meteorol 149(11):1919-1930. https://doi.org/10.1016/j.agrformet.2009.06.020

Grömping U (2006) Relative importance for linear regression in R: The package relaimpo. J Stat Softw 17:925-933

Huang K, Xia J, Wang Y, Ahlstrom A, Chen J, Cook RB, Cui E, Fang Y, Fisher JB, Huntzinger DN (2018) Enhanced peak growth of global vegetation and its key mechanisms. Nat Ecol Evol 2(12):1897-1905. https://doi.org/10.1038/s41 559-018-0714-0

Huang X, Xiao J, Ma M (2019) Evaluating the performance of satellite-derived vegetation indices for estimating gross primary productivity using FLUXNET observations across the globe. Remote Sens 11(15):1823. https://doi.org/10.33 90/rs11151823

Huete A, Didan K, Miura T, Rodriguez EP, Gao X, Ferreira LG (2002) Overview of the radiometric and biophysical performance of the MODIS vegetation indices. Remote Sens Environ 83(1-2):195-213. https://doi.org/10.1016/ S0034-4257(02)00096-2

Janssens IA, Lankreijer H, Matteucci G, Kowalski AS, Buchmann N, Epron D, Pilegaard K, Kutsch W, Longdoz B, Grünwald T, Montagnani L, Dore S, Rebmann C, Moors EJ, Grelle A, Rannik Ü, Morgenstern K, Oltchev S, Clement R, Guðmundsson J, Minerbi S, Berbigier P, Ibrom A, Moncrieff J, Aubinet M, Bernhofer C, Jensen NO, Vesala T, Granier A, Schulze E-D, Lindroth A, Dolman AJ, Jarvis PG, Ceulemans R, Valentini R (2001) Productivity overshadows temperature in determining soil and ecosystem respiration across European forests. Glob Chang Biol 7(3):269278. https://doi.org/10.1046/j.1365-2486.2001.00412.x

Keenan TF, Gray JM, Friedl MA, Toomey M, Bohrer G, Hollinger DY, Munger JW, Okeefe J, Schmid HP, Wing IS (2014) Net carbon uptake has increased through warming-induced changes in temperate forest phenology. Nat Clim Chang 4(7):598-604. https://doi.org/10.1038/nclimate2253

Körner C (2015) Paradigm shift in plant growth control. Curr Opin Plant Biol 25: 107-114. https://doi.org/10.1016/j.pbi.2015.05.003

Lasslop G, Reichstein M, Papale D, Richardson AD, Arneth A, Barr A, Stoy P, Wohlfahrt G (2010) Separation of net ecosystem exchange into assimilation and respiration using a light response curve approach: critical issues and global evaluation. Glob Chang Biol 16(1):187-208. https://doi.org/10.1111/j.13 65-2486.2009.02041.x

Li X, Xiao J (2020) Global climatic controls on interannual variability of ecosystem productivity: Similarities and differences inferred from solar-induced chlorophyll fluorescence and enhanced vegetation index. Agric For Meteorol 288-289:108018. https://doi.org/10.1016/j.agrformet.2020.108018

Liu F, Wang X, Wang C (2019a) Autumn phenology of a temperate deciduous forest: Validation of remote sensing approach with decadal leaf-litterfall measurements. Agric For Meteorol 279:107758. https://doi.org/10.1016/j.a grformet.2019.107758

Liu F, Wang X, Wang C (2019b) Measuring vegetation phenology with near-surface remote sensing in a temperate deciduous forest: effects of sensor types and deployments. Remote Sens 11(9):1063. https://doi.org/10.3390/rs11091063

Liu F, Wang C, Wang X (2021a) Sampling protocols of specific leaf area for improving accuracy of the estimation of forest leaf area index. Agric For Meteorol 298-299:108286. https://doi.org/10.1016/j.agrformet.2020.108286

Liu F, Wang X, Wang C, Zhang Q (2021 b) Environmental and biotic controls on the interannual variations in $\mathrm{CO}_{2}$ fluxes of a continental monsoon temperate forest. Agric For Meteorol 296:108232. https://doi.org/10.1016/j.agrformet.2020.108232

Lloyd J, Taylor J (1994) On the temperature dependence of soil respiration. Funct Ecol 8(3):315-323. https://doi.org/10.2307/2389824

Lu X, Liu Z, Zhou Y, Liu Y, An S, Tang J (2018) Comparison of phenology estimated from reflectance-based indices and solar-induced chlorophyll fluorescence (SIF) observations in a temperate forest using GPP-based phenology as the standard. Remote Sens 10(6):932

Marcolla B, Cescatti A (2018) Geometry of the hemispherical radiometric footprint over plant canopies. Theor Appl Climatol 134(3-4):981-990. https://doi.org/1 0.1007/s00704-017-2326-z

Mbow C, Fensholt R, Rasmussen K, Diop D (2013) Can vegetation productivity be derived from greenness in a semi-arid environment? Evidence from groundbased measurements. J Arid Environ 97:56-65. https://doi.org/10.1016/j.ja ridenv.2013.05.011

Musavi T, Migliavacca M, Reichstein M, Kattge J, Wirth C, Black TA, Janssens IA, Knohl A, Loustau D, Roupsard O (2017) Stand age and species richness dampen interannual variation of ecosystem-level photosynthetic capacity. Nat Ecol Evol 1(2):48-48. https://doi.org/10.1038/s41559-016-0048 
Nagai S, Saigusa N, Muraoka H, Nasahara KN (2010) What makes the satellitebased EVI-GPP relationship unclear in a deciduous broad-leaved forest? Eco Res 25(2):359-365. https://doi.org/10.1007/s11284-009-0663-9

Noormets A, Desai AR, Cook BD, Euskirchen ES, Ricciuto DM, Davis K, Bolstad PV, Schmid HP, Vogel CV, Carey EV, Su HB, Chen J (2008) Moisture sensitivity of ecosystem respiration: Comparison of 14 forest ecosystems in the Upper Great Lakes Region, USA. Agric For Meteorol 148(2):216-230. https//doi.org/10.1016/j.agrformet.2007.08.002

Park T, Ganguly S, Tommenvik H, Euskirchen ES, Hogda KA, Karlsen SR, Brovkin V, Nemani RR, Myneni RB (2016) Changes in growing season duration and productivity of northern vegetation inferred from long-term remote sensing data. Environ Res Lett 11(8):084001. https://doi.org/10.1088/1748-9326/11/8/084001

Peng D, Wu C, Li C, Zhang X, Liu Z, Ye H, Luo S, Liu X, Hu Y, Fang B (2017a) Spring green-up phenology products derived from MODIS NDVI and EVI: Intercomparison, interpretation and validation using National Phenology Network and AmeriFlux observations. Ecol Indic 77:323-336. https://doi.org/1 0.1016/j.ecolind.2017.02.024

Peng D, Zhang X, Wu C, Huang W, Gonsamo A, Huete A, Didan K, Tan B, Liu X, Zhang B (2017b) Intercomparison and evaluation of spring phenology products using National Phenology Network and AmeriFlux observations in the contiguous United States. Agric For Meteorol 242:33-46. https://doi.org/1 0.1016/j.agrformet.2017.04.009

Piao S, Wang X, Wang K, Li X, Bastos A, Canadell J, Ciais P, Friedlingstein P, Sitch $S$ (2019) Interannual variation of terrestrial carbon cycle: Issues and perspectives. Glob Chang Biol 26:300-318

Rahman AF, Sims DA, Cordova VD, Elmasri B (2005) Potential of MODIS EVI and surface temperature for directly estimating per-pixel ecosystem C fluxes. Geophys Res Lett 32(19):L19404. https://doi.org/10.1029/2005GL024127

Reichstein M, Falge E, Baldocchi D, Papale D, Aubinet M, Berbigier P, Bernhofer C, Buchmann N, Gilmanov T, Granier A, Grünwald T, Havránková K, Ilvesniemi H, Janous D, Knohl A, Laurila T, Lohila A, Loustau D, Matteucci G, Meyers T, Miglietta F, Ourcival J-M, Pumpanen J, Rambal S, Rotenberg E, Sanz M, Tenhunen J, Seufert G, Vaccari F, Vesala T, Yakir D, Valentini R (2005) On the separation of net ecosystem exchange into assimilation and ecosystem respiration: review and improved algorithm. Glob Chang Biol 11(9):14241439. https://doi.org/10.1111/j.1365-2486.2005.001002.x

Richardson AD, Klosterman S, Toomey M (2013) Near-Surface Sensor-Derived Phenology, Phenology: An Integrative Environmental Science. Springer Netherlands, pp 413-430

Rocha A, Shaver G (2009) Advantages of a two band EVI calculated from solar and photosynthetically active radiation fluxes. Agric For Meteorol 149(9): 1560-1563

Running SW, Nemani RR, Heinsch FA, Zhao M, Reeves M, Hashimoto H (2004) A continuous satellite-derived measure of global terrestrial primary production. BioScience 54(6):547-560. https://doi.org/10.1641/0006-3568(2004)054[0547:A CSMOG]2.0.CO;2

Ryu Y, Berry JA, Baldocchi DD (2019) What is global photosynthesis? History, uncertainties and opportunities. Remote Sens Environ 223:95-114. https:// doi.org/10.1016/j.rse.2019.01.016

Schmid HP (2002) Footprint modeling for vegetation atmosphere exchange studies: a review and perspective. Agric For Meteorol 113(1-4):159-183. https://doi.org/10.1016/S0168-1923(02)00107-7

Sesnie SE, Dickson BG, Rosenstock SS, Rundall JM (2012) A comparison of Landsat TM and MODIS vegetation indices for estimating forage phenology in desert bighorn sheep (Ovis canadensis nelsoni) habitat in the Sonoran Desert, USA. Int J Remote Sens 33(1):276-286. https://doi.org/10.1080/01431161.2011.592865

Shen M, Tang Y, Desai AR, Gough C, Chen J (2014) Can EVl-derived land-surface phenology be used as a surrogate for phenology of canopy photosynthesis? Int J Remote Sens 35(3):1162-1174. https:/doi.org/10.1080/01431161.2013.875636

Shi H, Li L, Eamus D, Huete A, Cleverly J, Tian X, Yu Q, Wang S, Montagnani L, Magliulo V, Rotenberg E, Pavelka M, Carrara A (2017) Assessing the ability of MODIS EVI to estimate terrestrial ecosystem gross primary production of multiple land cover types. Ecol Indic 72:153-164. https://doi.org/10.1016/j. ecolind.2016.08.022

Sonnentag O, Hufkens K, Teshera-Sterne C, Young AM, Friedl M, Braswell BH, Milliman T, O'Keefe J, Richardson AD (2012) Digital repeat photography for phenological research in forest ecosystems. Agric For Meteorol 152:159-177. https://doi.org/10.1016/j.agrformet.2011.09.009

Sun X, Liu F, Zhang Q, Li Y, Zhang L, Wang J, Zhang H, Wang C, Wang X (2021) Biotic and climatic controls on the interannual variation in canopy litterfall of a deciduous broad-leaved forest. Agric For Meteorol 307:108483. https://doi. org/10.1016/j.agrformet.2021.108483
Tramontana G, Migliavacca M, Jung M, Reichstein M, Keenan TF, Camps-Valls G, Ogee J, Verrelst J, Papale D (2020) Partitioning net carbon dioxide fluxes into photosynthesis and respiration using neural networks. Glob Chang Biol 26(9): 5235-5253. https://doi.org/10.1111/gcb.15203

Verma M, Friedl MA, Richardson AD, Kiely G, Cescatti A, Law BE, Wohlfahrt G, Gielen B, Roupsard O, Moors EJ (2014) Remote sensing of annual terrestrial gross primary productivity from MODIS: An assessment using the FLUXNET La Thuile data set. Biogeosciences 11(8):2185-2200. https://doi.org/10.5194/bg-11-2185-2014

Vermote E (2015) MOD09A1 MODIS/Terra Surface Reflectance 8-Day L3 Global $500 \mathrm{~m}$ SIN Grid V006. NASA EOSDIS Land Processes DAAC

Wang Q, Tenhunen J, Dinh NQ, Reichstein M, Vesala T, Keronen P (2004) Similarities in ground- and satellite-based NDVI time series and their relationship to physiological activity of a Scots pine forest in Finland. Remote Sens Environ 93(1-2):225-237. https://doi.org/10.1016/j.rse.2004.07.006

Wang X, Wang C, Guo Q, Wang J (2016) Improving the $\mathrm{CO}_{2}$ storage measurements with a single profile system in a tall-dense-canopy temperate forest. Agric For Meteorol 228-229:327-338. https://doi.org/10.1016/j.a grformet.2016.07.020

Wang S, Zhang Y, Ju W, Qiu B, Zhang Z (2021) Tracking the seasonal and interannual variations of global gross primary production during last four decades using satellite near-infrared reflectance data. Sci Total Environ 755: 142569. https://doi.org/10.1016/j.scitotenv.2020.142569

Wylie BK, Johnson DA, Laca E, Saliendra NZ, Gilmanov TG, Reed BC, Tieszen LL, Worstell BB (2003) Calibration of remotely sensed, coarse resolution NDVI to $\mathrm{CO}_{2}$ fluxes in a sagebrush-steppe ecosystem. Remote Sens Environ 85(2): 243-255. https://doi.org/10.1016/S0034-4257(03)00004-X

Xia J, Niu S, Ciais P, Janssens IA, Chen J, Ammann C, Arain A, Blanken PD, Cescatti A, Bonal D (2015) Joint control of terrestrial gross primary productivity by plant phenology and physiology. Proc Natl Acad Sci U S A 112:2788-2793

Xia J, Wang J, Niu S (2020) Research challenges and opportunities for using big data in global change biology. Glob Chang Biol 26(11):6040-6061. https:// doi.org/10.1111/gcb.15317

Xu X, Du H, Fan W, Hu J, Mao F, Dong H (2019) Long-term trend in vegetation gross primary production, phenology and their relationships inferred from the FLUXNET data. J Environ Manag 246:605-616. https://doi.org/10.1016/j. jenvman.2019.06.023

Yang H, Yang X, Zhang Y, Heskel MA, Lu X, Munger JW, Sun S, Tang J (2017) Chlorophyll fluorescence tracks seasonal variations of photosynthesis from leaf to canopy in a temperate forest. Glob Chang Biol 23(7):2874-2886. https://doi.org/10.1111/gcb.13590

Yin G, Verger A, Filella I, Descals A, Peñuelas J (2020) Divergent estimates of forest photosynthetic phenology using structural and physiological vegetation indices. Geophys Res Lett 47:e2020GL089167

Zhao B, Donnelly A, Schwartz MD (2020) Evaluating autumn phenology derived from field observations, satellite data, and carbon flux measurements in a northern mixed forest, USA. Int J Biometeorol 64(5):713-727

Zhou Y (2020) Relative contribution of growing season length and amplitude to long-term trend and interannual variability of vegetation productivity over Northeast China. Forests 11(1):112. https://doi.org/10.3390/f11010112

Zhou L, Tucker CJ, Kaufmann RK, Slayback D, Shabanov NV, Myneni RB (2001) Variations in northern vegetation activity inferred from satellite data of vegetation index during 1981 to 1999. J Geophys Res 106(D17):20069-20083. https://doi.org/10.1029/2000JD000115

Zhou S, Yu B, Huang Y, Wang G (2014) The effect of vapor pressure deficit on water use efficiency at the subdaily time scale. Geophys Res Lett 41:5005-5013

Zhou S, Zhang Y, Caylor KK, Luo Y, Xiao X, Ciais P, Huang Y, Wang G (2016) Explaining inter-annual variability of gross primary productivity from plant phenology and physiology. Agric For Meteorol 226-227:246-256. https://doi. org/10.1016/j.agrformet.2016.06.010

Zhou S, Zhang Y, Ciais P, Xiao X, Luo Y, Caylor KK, Huang Y, Wang G (2017) Dominant role of plant physiology in trend and variability of gross primary productivity in North America. Sci Rep 7(1):41366. https://doi.org/10.1038/srep41366

\section{Publisher's Note}

Springer Nature remains neutral with regard to jurisdictional claims in published maps and institutional affiliations. 